\title{
Eco-Catastrophe in The Wind From Nowhere
}

\author{
Miss Anisha \\ Research Scholar \\ Dept. of English and Foreign Languages \\ Maharshi Dayanand University \\ Rohtak, India \\ anishadahiya095@gmail.com
}

\begin{abstract}
:
Ecocriticism constitutes the fictional treatment of environmental problems. Climate Change is one of the biggest threats the world is facing today. There are alarming debates signaling constant fear of the grave consequences that can be triggered by the global warming. Newspapers are literally filled with articles on the topic of climate change. Sea levels are rising like anything and oceans are becoming warmer. The Wind From Nowhere is one of the insightful novels in the contemporary age where Ballard prophesizes the vision of an ecocatastrophe triggered by human induced global warming leaving earth totally unfit for human survival which can turn into reality anytime. The aim of this paper is to explore how Ballard portrays that vision of eco-catastrophe using the metaphor of cyclonic winds which create havoc all over the world. It also illustrates the creepy imageries and undertones of the catastrophic setting presented in the novel, in which people are reduced to beastly mode of survival. Particular emphasis is given on the psychological effects of the altered environment on the characters in the novel. Ballard portrays his characters to be trapped between an old dead world and a terrifying incomprehensible new one.
\end{abstract}

Keywords: Ecocriticism, Climate Change, Tipping Point, Eco-Catastrophe 
Ecocriticism has emerged as a significant branch in the field of literary criticism. It basically emerged as a response to the climate change and environmental problems. It is an area of literary criticism that emerged in the 1980s and 1990s in American studies as an attempt to direct our consciousness to an understanding of nature previously being ignored or rather neglected. The term "eco-criticism" was used for the very first time by William Rueckert in his essay "Literature and Ecology: An Experiment in Eco-criticism" (1978) but it came out in real sense through the seminal work of Cheryll Glotfelty The Ecocriticism Reader. It portrays the "interrelationship of nature and human emphasizing how human culture is connected to the physical world, affecting it and affected by it"(Glotfelty 101). It aims to create an ecological awareness among people by literary works.

The Wind From Nowhere is the first novel of James Graham Ballard. It is his first literary foray into ecocritical fiction. It aims to present the fragility of human beings in front of nature. Nature has turned hostile towards human beings responsible for the environmental degradation. It is one of the prescient novels in present times when there are frequent discussions on climate change and catastrophic events. It portrays vision of a "Tipping Point" where to quote Pramod K Nayar (Ecoprecarity: Vulnerable Lives in Literature and Culture) "our living world is irreversibly altered" which can be triggered anytime today itself if the menace of global warming is not curbed. Global Warming is increasing day by day due to the anthropogenic emissions of greenhouse gases. Climate Change has aggravated our vulnerability towards catastrophic events such as flash floods, freakish hurricanes, massive wildfires, severe droughts, sudden landslides. It has been manifested again in the very recent incident of New South Wales bushfire which was triggered by high temperature followed by severe drought. The fire leads to destruction of enormous flora and fauna along with deaths of many people. This awareness has also been underscored just a couple of weeks back by Lewis Pugh, a British South African Swimmer. He braved the freezing temperatures of the 
Antarctic ice during his 10 minutes swim in order to ring a bell of terrifying climate change manifested in the large gaps between melting water and the ice sheets of the glacier triggered by high temperatures and the tendency of the melting water to fall into oceans anytime. He said as quoted in "Lewis Pugh swims under melting Antarctic ice sheet" (BBC News)

"I swam here today as we are in a climate emergency. We need immediate action from all nations to protect our planet."

The Wind From Nowhere, makes us peep into a scenario of eco catastrophe , using the metaphor of an increasing strong wind, which constantly blows from west to east ,begins to collapse buildings worldwide, forcing people to live underground to survive. The most striking feature of the novel lies in Ballard's shift from a blame on anthropogenic activities to an implied warning of the offspring of global warming evident in the very hostile climate turning most part of the city totally unfit for the survival of humans. The characters literally struggle for fresh air to breathe.

"The air was full of large pieces of grit that flicked and stung at their faces like angry insects." (Ballard 105)

The very beginning of the novel takes us into the midst of winds that are destroying everything coming in their way. Ballard describes the winds brimming in terrifying power:

"Widespread havoc is reported from many parts of the world, particularly in the Far East and the Pacific, where tens of thousands are homeless. Winds of up to hurricane force have flattened entire towns and villages, causing heavy flooding and hampering the efforts of rescue workers." (Ballard19)

Ballard employs vivid imageries and apt words in order to highlight the nature of hurricane. He stresses that the wind came from nowhere, meaning that its cause is unknown and uses expressions such as" flatten "and "heavy" to convey the immense power and the destructive nature of the natural phenomenon. As Gregory Stephenson (42) says, " The nature 
of cataclysm is a global cyclone whose wind velocity ultimately reaches $550 \mathrm{mph}$, destroying nearly every surface structure on the face of the earth and inflicting untold millions of causalities."

Ballard presents the nature in the form of winds which have turned hostile and indifferent towards human beings. Human Beings have indiscriminately exploited earth in the name of progress with their scientific weapons. Nature has now striked back at them in the form of violent cyclonic winds turning all the so-called advanced cities into hell cities.

"the deliberate act of an outraged Providence, determined to sweep man and his pestilience from the surface of this once green earth." (Ballard 48)

The cyclonic winds have encircled the whole world into its fury. No advanced nation is outside its clutches be it New York, Tokyo, Venice, Capetown, Singapore or others. The wind has taken the lives of a number of people. The wind sweeps all manmade symbols of progress which includes skyscraper of capital, New York City or Nelson's column, Statue of Liberty or London Bridge. The human inventions are knocked down one by one by the wind as if to serve as a rebuke to an overblown and overbearing race. The destruction of such monuments is seen as the destruction of anthropocentric attitude of humankind. Ballard by portraying of destruction of world-famous monuments intends to suggest that whatever the man has created can be destroyed within the fractions of second and this demonstration gives a direct hint to man to surrender to the supreme power of nature. (Lingras 74)There is a subtle message that man's intellect and reason cannot withstand the nature's power.

Ballard employs vivid and surreal imageries to illustrate how Earth symbolized once the abode of mankind is turning into a choking world doing away most of the humankind. It has turned into a nightmarish zone for its inhabitants owing to the as phyxiating atmosphere of extreme winds leading them to a slow death. The strange and unhealthy atmosphere have immensely destroyed the normal life of previous inhabitants of the city. It presents the 
fragility of humankind who with their scientific weapons are unable to stop the natural disaster. The so-called scientists fail even to get the correct cause of the ever-increasing catastrophe. All the governments come together in order to find a solution but fell down terribly.

Ballard subtly portrays the psychological effects on the human beings trying to survive the ecological disaster. All the characters turn against each other in a desperate battle for survival. In order to escape from the collapsing structures and wind driven debris on the surface, the people are forced to take refuge underground. They are literally forced to live like rats in their respective moles thereby reflecting their state of pure hopelessness:

"a sub-world of dark labyrinthine tunnels and shafts crowded with countless thousands of almost motionless beings, huddled together on the unlit platforms with their drab bundles of possessions, waiting patiently for the wind to subside, like the denizens of some vast gallery of the dead waiting for their resurrection." (Ballard 122)

They struggle against not only wind but also aggravating food and water crisis. The picture has now changed with humans who have once claimed the vast lands of this planet are now stuck in small, narrow areas beneath the ground. The scene lays bare the fact how unprepared humans are against the impact of nature's sweeping intensity.

The abnormal environment leads to a drastic change in the behavioral patterns of the characters. They turn victims of strange and dreadful dreams akin to horror movies. They fail to differentiate between the dream and reality. Feelings of uncertainty, ambiguity and doubt take the charge. They desperately try to survive the dreary landscape. Their attempts are constantly defeated by swift winds enclosing them like parachute. They exist in a psychic limbo between the destruction of artificial man-made environment and dysfunctional natural environment. Dr. Maitland emerges as the embodiment of the deepest psychological crisis triggered by the alien environment. He fantasizes that he is severely wounded and blinded. In 
fact, because of his tired body and daunted subconscious mind, he goes on fantasizing eerie things. He has succumbed to the hallucination owing trauma. He imagines himself to be in a hospital with other patients. Even after gaining full consciousness he could hear feeble voices of doctors behind the walls. Moreover, the characters adapt a beastly mode of survival to the verge of killing each other. Kroll tries to kill Symington and Marshall. Everyone is trying to preserve his interest as for instance Marshal wants to leave the place of havoc along with Deborah only leaving rest of his team including Symington, Kroll, and Chrighton behind to die. The basic human values of humility, compassion, respect and empathy take a back seat in the picture.

The struggle between man and nature is presented in the novel most vividly through the character of Hardoon and monstrous wind. Hardoon symbolizes the modern man who has developed arrogance due to the scientific knowledge and the Hardoon Tower is a symbol of human endeavour to gain control over nature. He boasts that he can conquer everything with the aid of technology including nature. He refuses to bow down before nature. He denounces the other people as weak reduced to bunkers, tunnels, sewer like insects and worms yielded to the nature. Hardoon is seen very arrogant, bold and confident about his experiment of erecting a pyramid like structure to overcome nature.

However, the novel at the end depicts that in spite of having a treasure of immense resources of technology, power and wealth Hardooon fails to defeat the wind. By depiction of the destruction of the pyramid, Ballard wants to point out that man can never be superior to nature. The power and supremacy of nature is unchallengeable. It doesn't matter if walls of the pyramid are 30 feet thick fully capable to face the impact of a dozen hydrogen bombs or capable to withstand ten-thousand-mile-an hour gales, it is ultimately buried down by one of the powerful forms of nature. The novel ends with an image of enormous Pyramid being shaken by the speedy wind and destroyed completely under huge drifts of dust. Thus, the 
wind projected in the novel reveals the immense power of nature and through the character of Hardoon, the ultimate reality of man's limitation is revealed. Gregory Stephenson rightly puts it:

"In the nature of Hardoon's struggle against the wind, and in his defeat, lies the symbolical meaning of the cataclysm." (43)

Conclusion:

In the light of above discussion, we can confidently conclude that The World From Nowhere is one of the prophetic works of climate change in the present times which highlights not only our vulnerability to the grave consequences of climate change but also the fragility of personality and individuality celebrated by us as our prized possessions. Ballard vividly portrays the event of eco catastrophe using the metaphor of cyclonic winds in the novel to reflect upon the worsening environmental crisis of today. He marvelously captures the threat of climate crisis and its grave consequences particularly the impossibility of human survival. At the heart of the novel lies the psychological effects of eco catastrophe on the characters confronted with an alien environment and their hopeless struggle against the catastrophe. It gives the ultimate message that there is no scope of survival for human beings unless and until they respect nature. The need of the hour is to address the climatic concerns in order to avoid such a nightmarish future. 


\section{Works Cited}

Ballard, J.G. The Wind from Nowhere.Berkley Books, 1961.

Glotfelty, Cheryll, and Harold Fromm, editors. The Ecocriticism Reader: Landmarks in Literary Ecology. Athens: U of Georgia Press, 1996.

Lingras,S.A. The Literary Ecology in the Select Novels of $J$ G Ballard A Study in Eco Criticism. 2017. Shivaji University. Ph.D. thesis. http://hdl.handle.net/10603/260267.

Nayar, Pramod K. Ecoprecarity: Vulnerable Lives in Literature and Culture. Routledge, 2019.

Stephenson, Gregory. Out Of The Night And Into The Dream: A Thematic Study of the Fiction of J.G. Ballard. Greenwood Press, 1991.

Tan, Cenk. An Ecocritical Study of J.G. Ballard's Climate Fiction Novels. 2019. Pamukkale University. Ph.D. thesis.doi: 10.13140/RG.2.2.24337.38240.

Trautman, Kelvin. "Lewis Pugh swims under melting Antarctic ice sheet." BBC News, 24 Jan. 2020, https://www.bbc.com/news/uk-england-devon-51212433. 